\title{
O Ministério Público e as Unidades de Conservação
}

\author{
Soraya Carvalhedo Honorato ${ }^{1, *}$, Isabel Maria Sampaio Oliveira Lima² \& Deborah Maria de Faria ${ }^{3}$
}

\author{
${ }^{1}$ Programa de Pós-Graduação em Desenvolvimento Regional e Meio Ambiente, \\ Universidade Estadual Santa Cruz - UESC \\ ${ }^{2}$ Programa de Pós-Graduação em Família na Sociedade Contemporânea, Universidade Católica de Salvador - UCSAL \\ ${ }^{3}$ Programa de Pós-Graduação em Ecologia e Conservação da Biodiversidade, Universidade Estadual Santa Cruz - UESC
}

Com o advento da Constituição Federal de 1988 a defesa do meio ambiente encontrou no Ministério Público (MP) um aliado de perfil diferenciado. Ao MP é atribuída a função de defender o meio ambiente, devendo não somente responsabilizar os causadores de danos ambientais, como também adotar medidas judiciais e extrajudiciais para evitar os possíveis danos. Fortalecido pela autoridade que a lei lhe confere, o MP dispõe de instrumentos efetivos para assegurar a conservação da natureza, reduzindo a distância entre a justiça e a comunidade científica, ampliando os mecanismos de sua participação social mediante a ação civil pública (judicial) e as audiências públicas (extrajudiciais). A comunidade científica pode encaminhar diretamente ao MP relatórios ou dados que considere substanciais para a proteção da natureza. Inaugurada esta ponte de corresponsabilidade, a sociedade civil e outros segmentos institucionais podem promover o cumprimento da lei, fortalecendo a educação para a conservação.

O MP constitui uma instituição dotada de meios para atuar em prol da seguridade ambiental, sobretudo das áreas protegidas, não somente por suas garantias e prerrogativas constitucionais, mas, igualmente, por força da sua autonomia administrativa e independência funcional. Esta independência do MP em relação ao Poder Executivo confere ao órgão ministerial uma prerrogativa constitucional que o coloca a salvo de eventuais interesses políticos ou econômicos que possam comprometer a punição administrativa do infrator ambiental.

O MP se destaca na área ambiental também por causa de determinadas fragilidades das organizações governamentais originalmente responsáveis pelas garantias dos interesses coletivos e difusos. Especificamente no âmbito do Corredor Central da Mata Atlântica da Bahia (CCMAB), já se

\footnotetext{
${ }^{*}$ Send correspondence to: Soraya Carvalhedo Honorato

Programa de Pós-Graduação em Desenvolvimento Regional e

Meio Ambiente,

Universidade Estadual Santa Cruz - UESC, Vila 04,

Rod. Ituberá-Camamú, Km 10, CP 48, CEP 45435-000,

Ituberá, BA, Brasil

E-mail: sol.honorato@gmail.com
}

constatou, por exemplo, que a deficiência de quadros e de recursos disponíveis nos órgãos ambientais e de fiscalização do Poder Executivo tem inviabilizado o sistema de comando e controle (Fonseca et al. 2004). Apesar dos esforços governamentais para ampliar o quadro de agentes ambientais e investir na infraestrutura, a impunidade relativa aos crimes ambientais parece ser um precedente sem limites para infrações contínuas nas Unidades de Conservação (UC). O IBAMA e as agências ambientais estaduais são incapazes de apenar os infratores com eficiência, acarretando uma insignificante quitação das próprias multas impostas (Laurance 1999). Outra circunstância grave diz respeito à descentralização: os Conselhos Municipais de Defesa Ambiental - CODEMA, em sua maioria, têm pouca representatividade. Identifica-se um despreparo técnico generalizado nestas instâncias governamentais relativas ao meio ambiente, acompanhada de freqüente omissão do poder púbico, através dos secretários municipais de meio ambiente, face às agressões ambientais (Honorato 2003).

Por outro lado, estudo recente identifica que, apesar do seu potencial, o MP baiano também enfrenta desafios entre as fragilidades comuns às dos três Poderes (Honorato 2008). Constatou-se que a ausência de analistas periciais ambientais lotados nas comarcas do interior para atender as múltiplas necessidades da conservação da Mata Atlântica limita significativamente a atuação ministerial, resultando em lentidão na apuração das notícias de danos, na formalização da denúncia do crime ao Poder Judiciário e na punição dos infratores. Esta lentidão também se projeta na recuperação ou reversão da degradação ambiental deixando a área ainda mais vulnerável. Tão grande a demanda que o MP chega a priorizar os processos que parecem urgentes em detrimento de processos formados a partir de notícias de danos que aguardam investigação e despacho há seis anos ou mais. Inexiste um instrumento de avaliação para medir a atuação ministerial de forma qualitativa quanto à defesa ambiental. A não apropriação técnica de elementos conceituais fundantes do próprio Direito Ambiental na área da Mata Atlântica limita o efetivo exercício da função ministerial na defesa das 
Unidades de Conservação dentro desse importante bioma no Estado da Bahia. As deficiências quanto à infraestrutura, equipamentos e servidores administrativos nas promotorias regionais, por sua vez, limitam a defesa das UC. A própria ausência de participação cidadã da sociedade civil, enquanto titular dos bens ambientais, limita a defesa das UC pelos Promotores de Justiça. Ainda é débil a aproximação entre os CODEMA e o MP. Este órgão, apesar da sua missão institucional/constitucional em relação ao Estado Democrático de Direito, ainda não interage de forma construtiva com a sociedade civil na perspectiva na conservação ambiental. $\mathrm{Na}$ pesquisa constatou-se uma tendência do MP não ocupar o seu papel de agente educador na conservação da natureza, seja na relação com a sociedade civil/conselhos, seja na agilização das demandas. Na maioria dos procedimentos a localização do dano é vaga e incipiente, verificando-se na pesquisa que $72 \%$ das denúncias criminais foram decorrentes de inquéritos policiais requisitados por outros (a maioria pelo IBAMA). Mais de $76 \%$ inquéritos civis no período encontrarem-se estagnados em face do intervalo de mais de um ano entre o penúltimo ato e último ato. As informações técnicas na área ambiental e no acervo legislativo correspondentes necessárias para manusear as peças judiciais nas comarcas ainda são insuficientes, prejudicando a composição civil e a conseqüente reversão do dano ambiental. No balanço geral dos 337 procedimentos analisados das comarcas do CCMAB verificou-se que a atuação do MP está muito distante daquilo que estabelece a lei e do que a conservação exige.

Neste contexto de limitações identificadas, reflete-se sobre o necessário fortalecimento do Estado em prol das UC, tendo como eixo central o exercício de atuação concatenada entre o Ministério Público, o Poder Executivo e o Judiciário. Na prática, o MP emana vigor ao Poder Executivo quando se utiliza dos autos de infração e dos relatórios de fiscalização para realizar as suas audiências na presença do infrator e do seu representante legal, o advogado. Em termos objetivos a nova conformação aqui proposta, "Poder Executivo + Ministério Público", moraliza a imagem do órgão fiscalizador diante da sociedade, tornando o infrator ambiental informado de que há conexão fortalecida na atuação conjunta e que, portanto, as multas e os embargos não ficarão estagnados nos arquivos do IBAMA e dos demais órgãos integrantes do Sistema Nacional de Meio Ambiente - SISNUMA, como anteriormente ficavam.

O MP também fortalece o Poder Judiciário quando o aproxima do Poder Executivo, mediante cessão de relatórios técnicos e autos de infração com vistas a subsidiar e inspirar o julgamento coerente e a proposição de penas ao criminoso que venham a ser atinentes à gestão das UC, evitando penalidades avessas à causa ambiental como a frágil e desconexa determinação judicial para o réu ambiental doar cestas básicas para creches ou asilos.

Outrossim, o MP fortalece à própria instituição quando, na ausência de perito ambiental do órgão e não sendo o Promotor um especialista do direito ambiental, recorre aos relatórios técnicos que, bem fundamentados, lhes permite negociar com o advogado do infrator a reversão, mitigação e cessação do dano ambiental nos Termos de Ajustamento de Conduta - TAC.

Em análise ao planejamento estratégico do MP baiano a pesquisa em questão também constatou que o Núcleo da Mata Atlântica do MP da Bahia - NuMA, reunindo mais de setenta Promotores de Justiça, tem sido um importante vetor de mudanças na postura do órgão frente às questões ambientais, no âmbito do CCMAB. Para aproximar estes operadores de justiça ao direito ambiental e qualificá-los, o NuMA lançou o manual da Lei Penal Ambiental e os cadernos ambientais que elucidam as principais leis ambientais federais e estaduais. Tais institutos são discutidos em oficinas periódicas tendo como público os Promotores de Justiça e as organizações parceiras (representantes da sociedade civil e do poder público). Para fortalecer a relação entre os Poderes Executivo e Judiciário com o MP e tornar mais eficiente o sistema de proteção estadual da Mata Atlântica, o NuMA concebeu um sistema de informações geográficas (SIG) além de seis bases ambientais sediadas ao longo de todo o CCMAB. O MP é a instituição que coordena cada uma dessas bases onde estão estabelecidas as unidades regionais de fiscalização do Instituto de Meio Ambiente da Bahia - IMA compostas de técnicos ambientais de nível superior. Há também policiais militares à disposição e a perspectiva de integrar a polícia civil e o IBAMA, vez que já participam das operações de fiscalização coordenadas pelo MP.

Neste contexto e mesmo com as limitações do MP, o NuMA defende que este seja um elo forte entre os Poderes Executivo e o Poder Judiciário: i) porque tem o respaldo legal para impor ao infrator à mitigação, cessação ou impedimento dos impactos ambientais sugeridos por fiscais ambientais do Poder Executivo; ii) porque pode tornar factual a conservação in loco mediante os acordos extrajudiciais, também baseados em laudos periciais e relatórios de fiscalização emitidos pelo Poder Executivo e; iii) sobretudo, porque pode provocar o Poder Judiciário a educar e punir esses infratores, oferecendo como materialidade do fato (a infração ou crime ambiental) as provas do crime que são os laudos, relatórios técnicos, notificações e autos de infração (multas, embargos e demolições) administrativos emitidos por fiscais ambientais habilitados, também desse mesmo poder executivo.

Educar para conservação da natureza constitui uma forma concreta de leitura da lei mediante uma prática eficaz do MP. A lei, em si, é silente: precisa de intérpretes comprometidos com a vida.

\section{Agradecimentos}

Universidade Estadual Santa Cruz - UESC, Fundação O Boticário de Proteção À Natureza - FBPN, Fundação de Amparo a Pesquisa do Estado da Bahia - FAPESB, Instituto Floresta Viva, Núcleo da Mata Atlântica do Ministério Público - NuMA, Organização para Conservação de Terras - OCT, Universidade Católica de Salvador - UCSAL e Fazenda Sucupira. 


\section{Referências}

Fonseca GAB et al., 2004. Corredores de biodiversidade: o Corredor Central da Mata Atlântica. In Arruda MB and Sá LFSN (eds.). Corredores Ecológicos: uma abordagem integradora de ecossistemas no Brasil. Brasília: Instituto Brasileiro do Meio Ambiente e dos Recursos Naturais Renováveis. p. 47-65.

Honorato SC, 2003. Conselhos municipais de meio ambiente: um olhar sobre a trajetória de capacitação dos conselhos de Ituberá, Igrapiúna e Nilo Peçanha. Lavras. [Monograph]. Lavras: Departamento de Engenharia Florestal, Universidade Federal de Lavras.
Honorato SC, 2008. Análise da Atuação do Ministério Público nas Unidades de Conservação do Corredor Central da Mata Atlântica na Bahia. [Dissertation]. Ilhéus: Universidade Estadual de Santa Cruz.

Laurance WF, 1999. Reflections on the tropical deforestation crisis. Biological Conservation, 91:109-117.

Recebido: Fevereiro 2010

Primeira Decisão: Fevereiro 2010

Aceito: Fevereiro 2010 